\title{
PLANNING ON A PRIOR INTENTION
}

\author{
Facundo M. Alonso
}

$\prod$

THERE IS in the philosophy of action a debate about the nature of intention and of its relation to belief. According to doxasticism, intending to act is a special kind of belief that one will so act, or at least necessarily involves such a belief. ${ }^{1}$ For conativism, in contrast, intending to act is a conative attitude that need neither involve nor be identified with the belief that one will so act. ${ }^{2}$ The debate between such views of intention bears on several pressing problems in the philosophy of action and practical reasoning. Adherents of the former view point out that it is only by endorsing "the thesis that intention involves belief" that we can shed light on issues such as knowledge of intentional action, the grounds of the norms of rationality for intention such as means-end coherence and consistency, and the role that intention plays in facilitating further planning and coordinating action. ${ }^{3}$ Supporters of the latter view, of course, deny this. ${ }^{4}$

1 See, e.g., Grice, "Intention and Uncertainty"; Harman, "Practical Reasoning"; Davis, "A Causal Theory of Intending"; Velleman, Practical Reflection; Setiya, "Practical Knowledge"; and Marušić and Schwenkler, "Intending Is Believing." This view is also sometimes called "cognitivism" about intention; see Paul, "How We Know What We're Doing”; and Marušić and Schwenkler, "Intending Is Believing." I think, however, that "doxasticism" is a more felicitous label for it, as it stresses the connection of intention with the specific attitude of belief. The latter attitude shares with the attitudes of supposing, imagining, pretending, and so forth, the property of being a cognitive attitude. But belief is distinctive among such attitudes in having a special connection to the truth, that is, in being a doxastic attitude. For discussion, see, e.g., Velleman, "On the Aim of Belief."

2 The locus classicus is Bratman, Intention, Plans, and Practical Reason. See also Davidson, "Intending"; McCann, "Settled Objectives and Rational Constraints"; Mele, Springs of Action; Paul, "How We Know What We're Doing"; and Brunero, "Cognitivism about Practical Rationality."

3 The apt expression comes from Harman, "Practical Reasoning," 432. On the first issue, see esp. Velleman, Practical Reflection; and Setiya, Reasons without Rationalism, "Practical Knowledge," and "Practical Knowledge Revisited." On the second, see Harman, "Practical Reasoning"; Davis, "A Causal Theory of Intending"; Setiya, "Cognitivism about Instrumental Reason"; and Velleman, "What Good Is a Will?" Below I discuss how doxasticists tackle the third issue.

4 Paul addresses the first issue ("How We Know What We're Doing"); Bratman (Planning, 
Much of the recent literature has focused on how the cited debate bears on the first two issues mentioned above and only limited attention has been given to how it bears on the third. In this paper I attempt to remedy that deficit. I offer a systematic discussion of how the debate between doxasticism and conativism bears on the question of the role that intention plays in facilitating further planning and coordination. It is commonly thought that intention facilitates the coordination of action by allowing one to form further intentions for the future on the basis of the belief that one's former intention will be successfully executed. However, this thought is naturally deemed by doxasticists to present a serious challenge for conativist accounts of the cited phenomena, as conativism denies the existence of a necessary connection between intention and belief. Call this the Belief Challenge to conativist accounts of intention-based planning and coordination. This paper is an inquiry into that challenge and its implications for our theory of intention.

There are three main reactions that conativists have had —or, might have—in response. First, some have denied that the challenge is calling attention to a real problem altogether. It is not true, some conativists maintain, that in order for intention to facilitate coordination, it must involve or engage a belief concerning its successful execution. ${ }^{5}$ Second, others have argued that the cognitive (or doxastic) constraint that the challenge sets on intention-based coordination is too demanding, and that a weaker constraint-formulated in terms of either (full) belief about chances or credences-might do as well. ${ }^{6}$ These reactions represent two forms of skepticism—strong and weak — about the Belief Challenge. Finally, in opposition to those two reactions, some others have acknowledged the role of belief in success in intention-based coordination but found this compatible with conativism. ${ }^{7}$

I believe that the cited challenge raises genuine concerns for conativism. I also believe that none of the aforementioned reactions to it is adequate. In this

Time, and Self-Governance) and Brunero ("Cognitivism about Practical Rationality"), among others, address the second. How conativists address the third issue is the subject of my inquiry below.

5 Mele, Springs of Action.

6 Brunero, "Cognitivism about Practical Rationality"; Audi, "Intending" and "Intention, Cognitive Commitment, and Planning"; Davidson, "Reply to Pears." A note on terminology: I will often speak more broadly of "cognitive"-rather than of "doxastic"-constraints on intention-based coordination in order to leave open the possibility that the cognitive attitude responsible for framing such coordination is not belief. For the sake of consistency, I will similarly speak more broadly of "cognitive" — rather than of "doxastic" — constraints on intention.

7 Bratman, Intention, Plans, and Practical Reason. 
paper I propose an alternative answer to the challenge on behalf of conativism. My proposal rests basically on two theses. The first is methodological. While it is true that, as noted earlier, the question of the cognitive constraints on intention-based coordination is intimately connected to the question of the cognitive constraints on mere intending, it is also true that those questions are, in respects to be discussed below, distinct or independent questions. Call this the Independence Thesis. Philosophers on each side of the debate have in general seen the former question as a mere spin-off from the latter, and as a result they have failed to consider the former question in its own terms, as raising its own difficulties. I believe, in contrast, that appreciating the specific issues that the former question raises is crucial to understanding the coordinating role of intention. The second thesis I defend is substantive rather than methodological. I claim that the cognitive aspect of intention-based coordination is better understood not in terms of belief, but in terms of a different cognitive attitude, the attitude of reliance. Call this the Reliance Thesis. This thesis, and the theory of reliance that underpins it, I contend, afford conativism with a comprehensive account of that central aspect of coordination and a satisfactory answer to the associated challenge.

The paper is organized as follows. In section 1, I describe some of the main features of the conativist account of intention-based coordination and explain how the Belief Challenge originates. In sections 2 and 3 , I consider the aforementioned conativist reactions to it in turn and show why they ultimately fail. Consideration of such reactions will allow us to single out the specific form of intention-based planning and coordination that is the object of our inquiry, identify the respects in which the aforementioned two questions are independent, and produce a more compelling formulation of the cited challenge. In section 4, I show how appeal to the Reliance Thesis helps conativism to answer the question of the cognitive aspects of intention-based coordination and to successfully address that challenge. I conclude in section 5 with some implications of the current proposal for our theory of intention.

\section{THE BELIEF CHALLENGE AGAINST CONATIVISM}

Many of our daily activities are complex and call for the coordination of our present and future actions. Preparing tomato sauce, for example, often requires one to find a recipe, get the ingredients, and follow the recipe step by step. If one does not do this—say, if one adds the garlic before the oil is sizzling hot-the sauce will likely be ruined. Likewise, doing things with others requires one to coordinate one's actions with those of others. If you and I are to dance the tango, it must be the case that one of us leads while the other follows. 
It is widely agreed that intention plays an important role in facilitating intrapersonal and interpersonal coordination, a role that other conative attitudes, such as ordinary desire, cannot—or at least typically do not—play. Among contemporary philosophers, Michael Bratman has done most to stress and elucidate this role of intention. ${ }^{8}$ Bratman maintains that our capacity to form intentions (or "plans") about the future is in part a response to our need to coordinate our activities with ourselves and with others. Bratman argues that intention plays such a coordinating role partly because it involves a distinctive conative commitment to action. This commitment, Bratman thinks, has two dimensions. One of them has to do with the causal-motivational connection between intention and action. Intention, Bratman asserts, "controls" or settles action in that, normally, if one now intends to perform a certain action in the future, and one's intention persists, one will (at least try to) perform that action then. The other dimension of it concerns the role that intention plays in practical reasoning. When one intends to act in a certain way in the future, Bratman says, one is disposed to reason in two basic ways. First, one is disposed to see the issue of one's so acting as being settled in one's mind and to persist in that state of settledness until the time of action arrives. Second, one is disposed to engage in further reasoning aimed at the execution of that intention, where this includes forming intentions concerning means and excluding incompatible options from consideration in deliberation. Thus, it is partly because it involves such a two-dimensional, conative commitment, Bratman explains, that intention facilitates the coordination of action. ${ }^{9}$

It is important to note for our purposes that Bratman's explanation of the coordinating role of intention is consistent with his endorsement of conativism and thus is independent of the thesis that intention involves belief. Bratman thinks that such a thesis is subject to counterexample. Suppose, Bratman illustrates, that I intend to perform a difficult action-say, to carry out a difficult rescue operation. In such a case, I may be aware of my strong determination to succeed and yet be agnostic about success. On reflection, I may not believe that I will fail, but I may not believe that I will succeed, either. ${ }^{10}$ In Bratman's view, the

8 Bratman, Intention, Plans, and Practical Reason. For a pioneering discussion, see Harman, "Practical Reasoning," 438, 446-48. Cf. Grice, "Intention and Uncertainty," $270-72$.

9 Bratman, Intention, Plans, and Practical Reason, 15-17. As noted in the text, this constitutes in Bratman's view only part of the explanation of the coordinating role of intention. I presently concentrate on this part of Bratman's explanation, as this is the focus of the criticisms that give rise to the Belief Challenge. I discuss another key part of Bratman's explanation in section 3 .

10 Bratman, Intention, Plans, and Practical Reason, 38. For a recent defense of doxasticism in light of such cases, see Marušić, "Belief and Difficult Action." 
existence of cases such as this does not conclusively establish the falsity of the intention-belief thesis, but it nonetheless recommends that we seek an explanation of intention-based coordination - and, in fact, of any intention-related phenomenon-independent of it.

Some philosophers have found fault with Bratman's explanation of the coordination role of intention, however. They have argued that a conativist view of intention such as Bratman's does not sit well with a conception of this attitude as playing the cited coordinating role. J. David Velleman presses a forceful version of this objection in recent work. ${ }^{11}$ To appreciate its force, we must first consider the account of intention-based coordination that Velleman himself endorses. Like Bratman, Velleman thinks that intention coordinates action because it involves a characteristic commitment. Intention, Velleman writes, is a "mental commitment to act," an attitude that settles one's course of action in a way that "enables us and those around us to count on our performing particular actions in the future." ${ }^{12}$ However, Velleman also thinks, unlike Bratman, that this commitment is of a cognitive, rather than a conative, nature. The commitment distinctive of one's intention to act, Velleman asserts, is a "cognitive commitment to the truth" of the proposition that one will so act-where this is the commitment characteristic of the belief that one will so act. ${ }^{13}$ Moreover, and this is key to his account, Velleman maintains that this belief (or "cognitive commitment") "is what actually does the work ... what provides the basis for coordination."14 One's intention to act facilitates the coordination of one's activities in the further future because it allows one to plan some of those future activities on the basis of its (partly) constitutive belief that one will so act. ${ }^{15}$ To account for the coordinating role of intention, Velleman insists, we must endorse the thesis that intention involves belief. ${ }^{16}$

It is useful to understand Velleman's account of intention-based coordina-

Velleman, "What Good Is a Will?" 204-8; cf. Audi, "Intention, Cognitive Commitment, and Planning."

12 Vellman, Practical Reflection, 111; cf. review of Intention, Plans, and Practical Reason and "What Good Is a Will?" 195.

13 Velleman, "What Good Is a Will?" 204.

14 Velleman, "What Good Is a Will?" 208.

15 Strictly speaking, Velleman no longer speaks of intention as being (partly) constituted by "belief" - as he did in earlier work (Practical Reflection) — but by a "cognitive commitment to the truth," thus "leav[ing] open whether that cognitive commitment should be called a belief" ("What Good Is a Will?" 209n10). For ease of exposition, in this paper I stick to Velleman's earlier formulation.

16 Cf. Marušić and Schwenkler's weaker claim that intention-based coordination "is especially easy to understand if intentions are a kind of belief" ("Intending Is Believing," 320-21). 
tion as involving two separate ideas. The first is that one's intention to $\phi$ facilitates the coordination of action in part because it allows one (and others) to plan to $\psi$ in the future on the basis of the belief that one will $\phi$. The second is that such a belief, the belief that one will $\phi$, is (partly) constitutive of one's intention to $\phi$. Call an account that builds on such ideas Doxasticism about Coordination (DC). ${ }^{17}$

The two ideas enjoy considerable initial plausibility. The first can be broken down into two further components: the idea that intention facilitates coordination by way of a relevant belief, and the idea that intention facilitates coordination by way of a belief with a specific content, a belief in success. The former component finds support in a familiar and widely accepted view of the nature of belief. According to this view, it is a function of belief to cognitively guide or frame one's reasoning. In believing that $p$, one is disposed to, among other things, deliberate, plan, and act on the premise that $p .{ }^{18}$ Thus, according to DC, one's intention to $\varphi$ facilitates coordination partly because the belief it involves-namely, the belief that one will $\phi$-disposes one to plan one's future activities on the premise that one will $\phi$. Suppose that I intend to spend the weekend in Chicago. Since my intention involves the belief that I will be there, I can go ahead and plan my activities for the weekend. I can plan to attend the Chicago Bulls game on Saturday and plan to meet an old friend for lunch in Wicker Park on Sunday, all based on the premise that I will be there. Similarly, my friend can plan to meet me for lunch on Sunday, on the basis of his belief that (I intend to be in Chicago this weekend and that ultimately) I will be there. The latter component rests on the intuitive thought that, in order to coordinate one's actions, it is not sufficient for one to be able to plan and act on the belief that one has a certain intention; one must also, and more fundamentally, be able to plan and act on the belief that such an intention will be successfully executed. ${ }^{19}$ Lastly, the second idea advanced by DC guarantees that an attitude deemed necessary for intention-based planning and thus for facilitating coordination — namely, belief in success - will be present in the context in which such planning and coordination takes place.

Reflection on such ideas naturally raises a question as to whether Bratman's view can actually account for the coordinating role of intention. Those ideas indicate that intention coordinates action partly because it involves the belief that one's intention will be successfully executed. The worry is that in Bratman's view intention is compatible with agnosticism about success, and such agnosticism

Other supporters of DC include Harman, "Practical Reasoning"; and Grice, "Intention and Uncertainty."

See, e.g., Velleman, "On the Aim of Belief," 255-77; and Schwitzgebel, "A Phenomenal, Dispositional Account of Belief," 253.

Cf. Velleman, "What Good Is a Will?" 195. 
seems to undermine, rather than facilitate, coordination. As Velleman eloquently puts it:

The coordinating role of intentions would ... come into doubt if intentions did not involve a cognitive commitment. When an intention coordinates behavior, the agent and his associates proceed on the assumption of its being executed - which would be an odd way to proceed if the agent himself were agnostic on the question. If I am agnostic as to whether I will be in Chicago on [Saturday], why should anyone plan or act on the assumption of my being there $?^{20}$

In pressing this objection Velleman is in fact setting a challenge not just for Bratman's conativism but for any account of the coordinating role of intention that builds on that view of intention. ${ }^{21}$ Call any such an account Conativism about Coordination (cc). The challenge is for CC to explain how intention can facilitate further planning and coordination, given the common idea that intention can do this only in the presence of belief in success and given their rejection of the thesis that intention involves such a belief. That is the "Belief Challenge" to conativism I anticipated in the introduction to this paper. From a conativist perspective, Velleman's objection is best viewed not as denying the existence of a conative aspect to intention-based coordination, but as calling attention to the existence of a cognitive aspect to it as well, an aspect that, in Velleman's assessment, is not properly appreciated by conativist accounts. Thus, from this perspective, the Belief Challenge confronts the conativist with the task of giving an explanation of the cognitive aspect of the coordinating role of intention. In the next two sections, I consider some conativist responses to this challenge and show how this motivates important ideas and distinctions, which will assist us in formulating a more satisfactory response to it in section 4 .

\section{SKEPTICISM ABOUT COGNITIVE CONSTRAINTS ON INTENTION-BASED COORDINATION}

\subsection{Mele's Strong Skepticism and Two Forms of Planning on a Prior Intention}

In his defense of conativism, Alfred Mele anticipates a version of the Belief

20 Vellman, "What Good Is a Will?" 206.

21 It is an exceptionally pressing challenge for Bratman's conativism in particular, however, as in his view part of the point or "aim" of intention has to do with the role this attitude plays in coordination (Intention, Plans, and Practical Reason; "Intention, Belief, Practical, Theoretical," 41-42). 
Challenge and offers a skeptical response to it. ${ }^{22}$ Mele maintains that the role that intention plays in the coordination of action is parasitic on conative features of that attitude alone, such as its tendency to causally control action, persist through time, lead to the formation of intentions about means, and disregard incompatible options in deliberation. ${ }^{23}$ Accordingly, Mele asserts that the role that intention plays in coordination "need in no way depend upon" any beliefs one may have concerning its execution. " "There is nothing about coordinative capacity itself," Mele remarks, "that calls for ... belief constraints on intention." 25 As will become apparent below, in making this remark Mele is in fact rejecting not only the idea (mentioned in section 1 above) that the formation of an intention to act in the further future on the basis of a prior intention to act in the nearer future must be cognitively framed by the belief that one's prior intention will be successfully executed; he is also rejecting the idea that the formation of such a further intention must be framed by any cognitive attitude about the success of one's prior intention at all.

Mele takes his skepticism about cognitive constraints on intention-based coordination to draw support from everyday experience. It is worthwhile to consider Mele's main example in some detail:

There are three seconds left in the basketball game. The Pistons are behind by four points, and Dumars has just drawn a foul. The players have a standing plan for just this situation [but they] believe that their chances of executing this plan beyond his sinking the initial foul shot are slim.... [Now, if] Dumars does intend to execute his portion of the plan, his intention can help to coordinate his activities, including his interaction with his teammates... [Moreover,] some of Dumars's plans for the nonimmediate future may rest on his intention ... even though he believes that the odds are against him. For example, Dumars's intention ... may figure in the etiology of an intention (formed on his way to the foul line) to explain the strategy later, in a postgame interview. ${ }^{26}$

Mele, Springs of Action, ch. 8.

Mele, Springs of Action, 137. Mele takes himself to be following Bratman on this issue (Intention, Plans, and Practical Reason). As we will see in section 3, however, Mele's interpretation of Bratman's view is partially misguided, for in the latter view an appeal to conative features of intention is necessary but not sufficient to account for the role that this attitude plays in coordination.

24 Mele, Springs of Action, 138.

25 Mele, Springs of Action, 138.

26

Mele, Springs of Action, 137-38. 
Mele's central claim is that in the envisaged scenario Dumars may intend to execute his part of the team's strategy while failing to believe that his intention will be executed, and yet his intention may support both interpersonal and intrapersonal coordination. I think that Mele's claim faces serious difficulties, however. Consider the claim as it connects to interpersonal coordination. In the original formulation of the example, Mele identifies the actions that the players must coordinate with each other in order to win the game, but is silent about how Dumars's intention may facilitate such coordination and, especially, about how it may do this in light of his doubts about success. So, insofar as it connects to interpersonal coordination, Mele's claim is largely unargued for. The claim is also controversial, for it is widely accepted that normally when individuals act jointly they coordinate their actions by intending to do their parts on the assumption that the other participants (intend to and) will eventually do theirs. ${ }^{27}$ If Dumars and his teammate-say, Thomas-achieve successful coordination, that will be partly because, say, Dumars intends to sink a shoot on the assumption that Thomas's intention to pass the ball to Dumars is first carried out. Consider next Mele's claim as it regards intrapersonal coordination. The trouble here is that the example Mele uses in this regard misfires, for it describes a case that is relevantly different from the cases of intention-based coordination at which Velleman's Belief Challenge is directed.

We should distinguish between two forms of intention-based planning. First, one may form the intention to $\psi$ (for the more distant future) on the basis of one's prior intention to $\phi$ (for the nearer future) in a context in which one assumes that (one will $\psi$ only if one first $\phi$ s and consequently that) one's intention to $\psi$ will be executed only if one's intention to $\phi$ is first executed. ${ }^{28}$ In such cases, it is intuitive to suppose, the formation of one's intention to $\psi$ is cognitively framed by the assumption that one will $\phi$. My forming the intention to attend the Chicago Bulls game on Saturday on the basis of my prior intention to be in Chicago this weekend is a case in point. Here in intending to attend the game, I

27 See, e.g., Tuomela and Miller, "We-Intentions"; and Bratman, "Shared Intention" and Shared Agency. I discuss the issue further elsewhere (Alonso, "Shared Intention, Reliance, and Interpersonal Obligations"). In this paper I concentrate mainly on the role intention plays in intrapersonal coordination.

For ease of exposition, in what follows I use the expression "assuming that $p$ " to mean "having a relevant cognitive attitude that $p$ " and leave open-until section 4 - whether such a cognitive attitude must be belief. Note that this use of the term "assumption" diverges from a familiar use of it associated with Velleman's work, according to which to assume that $p$ is to have a specific type of cognitive attitude, different from belief ("The Guise of the Good," ${ }_{112-13}$ ). See section 4.2 for some similarities between Velleman's "assumption" and the attitude I call "reliance." 
assume that my prior intention to be in Chicago will be executed first. I do so partly because I assume that the execution of my intention to attend the game causally depends on the prior execution of my intention to be in Chicago. ${ }^{29}$ Call cases of planning on the presumed prior success of a prior intention "prior-success planning." Second, one may form the intention to $\psi$ on the basis of one's prior intention to $\phi$ in a context in which one does not assume that the execution of one's intention to $\psi$ causally depends on the execution of one's intention to $\phi$. In such cases, I suggest, the formation of one's intention to $\psi$ need not be framed by the assumption that one will $\phi$. Call these cases of "non-prior-success planning." A clear illustration is provided by familiar instances of means-end reasoning. Normally, when one forms the intention to pursue what one believes is a means to one's intended end, one is aware that one possesses such a prior intention for the end. But in such cases one need not, and typically does not, assume that the execution of one's intention for the means depends on the prior execution of one's intention for the end; normally, one believes the converse of this.

The foregoing distinction indicates that it is cases of prior-success planning, rather than cases of non-prior-success planning, that the Belief Challenge puts pressure - or, in any case, should put pressure-on conativism to account for. It also explains why Mele's example of the role that Dumars's intention may play in intrapersonal coordination misfires as a response to that challenge. It misfires because it is an instance of non-prior-success planning, rather than of prior-success planning. Mele imagines that during the game Dumars first forms the intention to do his part of the team's strategy and on the basis of that intention then goes on to form the further intention to later describe the team's strategy in a postgame interview. However, it is apparent that in this scenario Dumars need not assume that the execution of his intention for the future (postgame) depends on the prior execution of his intention for the present (game), for he may simply realize that the causal efficacy of his future-directed intention is compatible with the causal inefficacy of his present-directed intention. Therefore, a serious difficulty with Mele's skeptical response to the Belief Challenge is that it overlooks the foregoing distinction and cognitive aspect of prior-success planning, thus failing to appreciate the force of the challenge and consequently to provide a satisfactory answer to it.

Before going any further, I want to return briefly to the above-mentioned supposition that prior-success planning works by way of an assumption of prior success. Besides its intuitive appeal, I think two ideas work in tandem to lend

29 There are thus two respects in which my intention to be in Chicago is prior here: it is formed antecedently to the formation of my intention to attend the game; and its prior execution is causally necessary for the execution of my intention to attend the game. 
additional support to it. The first is owed to Donald Davidson and says that an "intention [to act in the future] assumes ... a certain view of the future." ${ }^{30}$ When one forms an intention to act in the future, one does so against the background of what one assumes that future to be like. This is, undoubtedly, an important idea. But it is also too general for our purposes. It does not suffice to explain why, in cases of prior-success planning, when forming an intention to $\psi$ on the basis of a prior intention to $\phi$, one's "view of the future" must include, in particular, the assumption that one's intention to $\phi$ will be carried out. Here we must solicit the contribution of a second, more specific, idea. In general, it makes sense to intend to do something in the future only if one assumes that the conditions one takes to be necessary for the successful execution of one's intention will eventually be satisfied. In cases of prior-success planning, one assumes that a necessary condition for the success of one's intention to $\psi$ for the more distant future is that one's prior intention to $\phi$ for the less distant future be executed first; and so, according to that second idea, in such cases it makes sense for one to intend to $\psi$ only if one assumes that one's intention to $\phi$ will be executed first. Therefore, although the issues are complex, I think that, when put together, the cited two ideas make plausible the supposition that when engaged in prior-success planning, in intending to act in the future on the basis of a prior intention, one takes such a future to include the fact that one's prior intention is carried out.

\subsection{Brunero's Weak Skepticism and a Distinction between Two Questions}

In recent work, John Brunero has offered an alternative skeptical response to the Belief Challenge. ${ }^{31}$ Rather than maintaining with Mele that belief in success is never required for intention-based planning, Brunero claims that the cited belief is not always required for such planning. ${ }^{32}$ Brunero's is thus a form of weak skepticism, as opposed to Mele's strong skepticism, about the existence of cognitive constraints on intention-based coordination. More positively, Brunero proposes a disjunctivist account of such constraints. Although in some cases one coordinates one's actions by planning to act on the basis of the belief that one's intention will be executed, Brunero maintains, in other cases one achieves such coordination by "plan[ning] in light of the probability" that it will be executed. ${ }^{33}$

Davidson, "Intending," 100. Although I borrow this idea from Davidson, I reject his famous identification of intention with value judgment ("Intending," 100). I discuss aspects of Davidson's view of intention in section 2.3. Brunero, “Cognitivism about Practical Rationality," 27-30. Mele, Springs of Action, 138; Brunero, "Cognitivism about Practical Rationality," 28; cf. Adams, "Trying with the Hope." 
Thus, Brunero contends, once we realize that intention-based planning need not be framed by belief in success, we see that the cited challenge vanishes and that acceptance of the intention-belief thesis is not necessary to account for the coordinating role of intention. ${ }^{34}$

The crux of Brunero's skeptical response to the Belief Challenge lies in his idea of planning to act in light of the probability of success of one's prior intention. The challenge, recall, is to account for prior-success planning-and, especially, for the possibility of such planning in contexts of agnosticism about success - in a way compatible with conativism. Initially, Brunero's idea seems well suited for the task. ${ }^{35}$ Suppose that I have doubts as to whether my intention to spend the weekend in Chicago will be executed; perhaps I just heard on the radio that airline workers are deciding whether to go on strike this weekend. According to Brunero's idea, in such a case I may assess the probability of success of the cited intention and form the further intention to attend the Bulls game in light of that assessment. ${ }^{36}$

advocate of conativism who proposes a form of disjunctivism about such constraints. Like Brunero, Holton maintains that one can plan to act either on an "all-out belief" in success or on a "partial belief" in success ("Partial Belief, Partial Intention," 52), though his conception of such beliefs is very different from Brunero's. See Holton, "Partial Belief, Partial Intention" and "Intention as a Model for Belief." The details are not to the point here. What matters is that Holton's idea of planning on a partial belief in success suffers from a problem of under-specification analogous to the one faced by Brunero's idea of planning in light of probabilities of success, discussed in the text below.

Brunero, "Cognitivism about Practical Rationality," 29.

This is not to say that Brunero's idea is aimed at accounting for only one such form of intention-based planning. See note 36 .

36 The example is mine. Brunero himself offers a series of interesting examples with the aim of illustrating the cited idea, but unfortunately none of them involves the phenomenon of prior-success planning. Here is one of them: "Suppose we are teammates on a basketball team and you intend to make a shot, and, aware of your intention, I position myself for a rebound. I'm clearly not proceeding on the assumption that you'll execute your intention. Had I proceeded on that assumption, I would have hurried back down the court to set up on defense.... And much the same goes for [you].... [You] might position [your] self for a rebound" ("Cognitivism about Practical Rationality," 28). Brunero is correct to claim that when I form the intention to position myself for a rebound in such a scenario I need not assume that you will make your shot. An explanation is found in the distinction introduced in section 2.1: in that scenario I need not assume that my getting the rebound depends on your actually making the shot. Indeed, it is plausible to add that when I form such an intention in that scenario, I do so on the assumption that you will fail in your attempt. (Basketball players are often taught to assume that every shot will be missed so they can position themselves for a rebound.) Thus, we may see the above-mentioned example by Brunero as calling attention to the fact that sometimes it can make sense for one to plan to act on the assumption of the failure, rather than of the success, of one's prior intention. Note that this invites 
I think that Brunero is right in noting that the assessment of the probability of success of one's prior intention can play a role in coordination (I will say more about related matters in sections 2.3 and 4.4). However, I also think that Brunero's intuitive idea of planning to act in light of the probability of success is insufficiently fleshed out. Brunero's basic idea, we just saw, is that sometimes one assesses the probability of success of one's intention to $\varphi$ and then plans to act in light of that probability assessment. Brunero seems to conceptualize such a probability assessment as a full belief with non-categorical content - that is, as one's believing that the probability of one's $\phi$-ing is (say) .7-rather than as a partial belief (credence) with categorical content-that is, as one's having (say) .7 credence that one will $\phi$. But there is a question as to what the process of planning to act in light of that probability assessment amounts to in Brunero's view. The question, in other words, is how such a form of planning works in one's psychology. As noted in section 1, when one plans to act in light of the belief that one will $\varphi$, one plans to act on the premise that one will $\phi$. But when one "plans [to act] in light of the probability" that one will $\phi$, what particular premise does frame one's planning in this case? Is it the premise that the probability that one will $\phi$ is (say) .7? And, if so, how does this form of planning differ from planning on the belief that one will $\phi$ ? Unfortunately, Brunero does not say, and this makes it difficult to assess his case for the existence of an alternative cognitive constraint on intention-based planning and hence the possibility of accounting for prior-success planning in terms of it.

Brunero concludes his discussion of the Belief Challenge with an argument against DC, which is worth examining for our purposes. Brunero begins by calling our attention to Robert Audi's view of the cognitive aspect of intention. ${ }^{37}$ According to Audi's view, intending to $\phi$ necessarily involves believing that one will $\phi$ or believing that one's $\phi$-ing is more probable than not-where the latter belief is understood as a full belief with non-categorical content. ${ }^{38}$ Brunero does not endorse Audi's view, but calls attention to it for polemical purposes. He argues that since such a view establishes a weaker cognitive constraint on intention than the one set by doxasticism, it is more successful than the latter view in accounting for the coordinating role of intention. For, unlike doxasticism, Brunero maintains, Audi's view can account for such a phenomenon not only in cases in which one plans one's future activities on the assumption of success, but also in

the question, however, of whether it is one's flat-out assumption of failure, rather than one's probability assessment about success, that actually does the cognitive work of framing one's planning in such cases. I discuss a related question in section 2.3.

Audi, "Intending."

38 Audi, “Intending," 395; cf. Audi, “Intention, Cognitive Commitment, and Planning," 376n4. 
(some) cases in which one "plans [such activities] in light of the probability" of success. ${ }^{39}$ Therefore, Brunero concludes, not only do we need not embrace doxasticism in order to account for the coordinating role of intention; we are better off embracing an alternative view to that end as well. Thus, Brunero seeks to turn the tables against Velleman's Belief Challenge to conativism.

Brunero's argument prompts two comments. First, the argument rests on the mistaken presumption that Audi's view gives precise content to Brunero's intuitive yet also elusive idea of planning in light of the probability of success. As said above, Audi's view does make precise the idea of there being a tight connection between intention and probability assessments of its success. It establishes that sometimes intention comes accompanied by the assessment that success is more probable than not, where this is understood in terms of a full belief with non-categorical content. But the view does not specify what it is for one to plan one's further activities on the basis of such a belief. Among other things, it does not indicate whether, and if so how, planning on the basis of the belief that success is more probable than not differs from planning on the basis of the belief that success is forthcoming. So, in this regard, Audi's view does not improve on Brunero's idea.

The preceding comment lends support to what I earlier dubbed the Independence Thesis, according to which the question of the cognitive constraints on intention-based coordination is distinct from the question of the cognitive constraints on mere intending. It suggests that an account of the former phenomenon does not simply fall out of an account of the latter. In order to construct an account of the former phenomenon partly on the basis of an account of the latter, it is necessary to explain how it is that the cognitive attitude said to constrain intention plays the role of framing further planning. DC is a paradigm example of one such account. For, as we saw, it builds not only on the thesis that intention involves (full) belief but also, and most crucially, on a well-established view of the framing role that (full) beliefs (with categorical contents) play in our practical reasoning in general.

Second, whatever we might think about Brunero's "turning the tables" argument against Velleman's Belief Challenge, we surely should not interpret it as a partial defense of conativism. For an appeal to a view of the cognitive constraints on intention such as Audi's in the context of the present discussion does not answer the challenge on behalf of conativism, but only reintroduces it in a weaker form. In order for intention to play its characteristic coordinating role-or so the new challenge might go-it must involve at a minimum the belief that its execution is more probable than not, yet it is not obvious how conativism could 
account for that role of intention, since this view rejects the existence of even that more minimal cognitive constraint on intention as well. ${ }^{40}$ To answer the Belief Challenge, the conativist must look elsewhere. Unless otherwise noted, henceforth by "intention-based planning" I will mean prior-success planning. This is what the conativist must seek an explanation of.

\subsection{A Davidsonian, Decision-Theoretic Alternative to Brunero's Weak Skepticism}

One possibility is to look at another view of the connection between intention and probability assessments of success, one that is in fact compatible with conativism, and ask whether such a view can serve as a bedrock for an alternative account of the cognitive aspect of intention-based planning and response to the Belief Challenge. According to one version of that view, in order for one to intend to $\phi$ one must have credence greater than zero that one will $\phi$, where such credence is a condition of possibility for, rather than a constitutive part of, the cited intention. Call this the Minimal Credal Constraint (MCC) on intention. The view is explicitly endorsed by Davidson. ${ }^{41}$ Davidson famously likens intention to a judgment that an action of a certain type is desirable, where this judgment is conceived of as a conative attitude. But he also maintains that "the existence of the intention entails the existence of ... a belief with a subjective probability greater than zero" that performance is forthcoming. ${ }^{42}$ Davidson conceives of the cited belief as having two features: it is, deep down, a partial belief (credence) with categorical content; and it is "not part of what [one] intend[s], but an assumption without which [one] would not have the intention." ${ }^{43}$ Hence the compatibility of MCC with Davidson's conativism. ${ }^{44}$

Davidson, "Intending” and "Reply to Pears"; Bratman, Intention, Plans, and Practical Reason; Mele, Springs of Action. Interestingly, Audi raises a version of this challenge against Bratman's view of intention in later work ("Intention, Cognitive Commitment, and Planning"). Audi remarks that it is only by "endorsing the belief condition" on intention that we can account for the coordinating role of this attitude and that this "add [s] to the plan-theoretical reasons for accepting [that condition]" ("Intention, Cognitive Commitment, and Planning," 377n11). In section 4, I dispute Audi’s remark.

Davidson, "Reply to Pears," and cf. "Intending."

42 Davidson, "Reply to Pears," 213.

Davidson, "Intending," 100; cf. "Reply to Pears," 212-13. In earlier work, Davidson talks of the cited belief as a (full) belief in the possibility of success: "an agent cannot intend what he believes to be impossible" ("Intending," 93, and see also 94, 100-1; "Reply to Pears," 212). Davidson's appeal to credences in later work ("Reply to Pears") is an attempt to make that earlier talk ("Intending") more precise. For further discussion, see Ludwig, "Impossible Doings."

44 MCC should be contrasted with what we may call partial doxasticism, a view according to which it is partly constitutive of one's intention to $\phi$ that one has credence greater than 
Having singled out a view of the connection between intention and probability assessments of success compatible with conativism—namely, MCC-the task now is to construct an account of the cognitive framing of intention-based planning on the basis of it. ${ }^{45}$ A preliminary point is that, typically, having credence greater than zero in performance shapes one's intention-based planning in a different way than belief in performance does. Suppose that I intend to be in Chicago this weekend. If I have a low (say, .2) credence that I will be in Chicago this weekend, I will also have, provided that I am rational, a high (.8) credence that I will not be there then. Other things being equal, in such a case I will be more willing to plan my activities for the weekend on the premise that I will not be in Chicago than on the premise that I will be in Chicago. For example, I will be more willing to plan to cook dinner at home on the premise that I will be at home (and thus not in Chicago) than to plan to attend the Bulls game on the premise that I will be in Chicago. Yet, on many occasions other things are not equal. I may have a low credence in the success of my prior intention to be in Chicago but assign a much higher value to the outcome facilitated by planning on its success (here, attending the Bulls game) than to the outcome facilitated by planning on its failure (here, cooking dinner at home). How one's credence in the execution of a prior intention shapes one's further planning will typically depend on other factors, such as how one evaluates relevant outcomes. And this indicates that, at least on many occasions, appeal to MCC will not suffice to explain how intention-based planning is cognitively framed.

As hinted at in the preceding paragraph, a natural proposal here is to supplement MCC with elements from which to construct a decision-theoretic account of the role of credences in planning. This is by no means an obvious task. Standard decision theory says that I would be justified in planning on $p$ - say, in planning on the success of my intention to be in Chicago - if the value I assign to this "act" is higher than the value I assign to relevant alternatives—say, to planning on the failure of my intention to be in Chicago. It also tells us that the value I assign to planning on $p$ depends on:

(a) my credence that I will (will not) achieve a certain outcome given that I plan on $p$-here: that I will (will not) attend the game given that I plan on the success of my intention to be in Chicago-where such credences

zero that one will $\phi$. See, e.g., Pears, "Intention and Belief," 78-79, 82; and Setiya, "Practical Knowledge," 391-92, 395-96, and "Practical Knowledge Revisited," 130.

45 It is not clear that this task has been undertaken by an advocate of MCC. Here I indicate how it might naturally be pursued. 
are a function of my credence that $p$-here: a function of my credence that I will be in Chicago; and

(b) the value I assign to the outcomes facilitated (not facilitated) by such planning - here: the value I assign to my attending (not attending) the game.

Thus, the foregoing decision-theoretic account offers a detailed explanation of what it is for one to be justified in planning on the premise that $p$. That said, we should remind ourselves that our main question here is primarily psychological, rather than normative. What we want to know is what roles the cited credences (which include one's credence that $p$ ) and evaluations play, if any, in cognitively framing one's planning on $p$ on such an account. A natural answer builds on two plausible claims. The first is that when such a set of credences and evaluations justifies one in planning on $p$, it disposes one to plan on $p$. The second is that to plan on $p$ is to plan on a relevant full—rather than partial—cognitive attitude that $p{ }^{46}$ The answer, then, is that when one is justified in planning on $p$, one has a set of credences and evaluations that leads one to form a full cognitive attitude that $p$, and that it is this latter attitude-rather than one's partial belief (i.e., credence) that $p$ - that plays the role of cognitively framing one's planning on $p$ in such cases.

A decision-theoretic account of the cognitive aspect of intention-based planning along the preceding lines deserves much more scrutiny than I can give in this paper. Having said that, I think the account, as so far elaborated, raises some worries. One of them is that it does not identify the full cognitive attitude responsible for framing one's planning. This indicates that the account, even if correct, is incomplete. ${ }^{47}$ Nevertheless, the main worry this account raises has to do in my view with the theoretical commitments that the conativist would have to take on if she were to embrace the cited decision-theoretic account. To arrive at such an account, the conativist would have to supplement MMC with the idea that in the context of intention-based planning one has the additional cre-

\section{See esp. Wright, "Warrant for Nothing (and Foundations for Free)?" 178-83.}

Ross and Schroeder offer an account that seems to fill in this lacuna, arguing that the relevant full cognitive attitude is belief ("Belief, Credence, and Pragmatic Encroachment"). In a similar vein, Holton speaks in recent work of (full) belief "as providing a stable coordination point" and as "underpinned by practical considerations" ("Intention as a Model for Belief," 15, 16). In my view, practical considerations play a preeminent role, not in belief, but in a different cognitive attitude, the attitude of reliance (Alonso, "What Is Reliance?" and "Reasons for Reliance"). I return to these issues in section 4. For critical discussion of how practical considerations enter into Holton's account of belief, see Bratman, "Rational and Social Agency," 308-10. 
dences and has made the evaluative judgments mentioned above. But this idea encounters an objection often leveled against decision-theoretic explanations of psychological phenomena in general, namely, that it makes the present account of intention-based planning too demanding. For non-ideal agents like us engage in such planning and yet often lack the time, energy, and intellectual resources to go through the relevant calculations leading to the assignments of probability and utility-i.e., credences and evaluations - that constitute the backbone of the present account. ${ }^{48}$ Given this, I think the conativist is well advised to construct an account of intention-based planning that is neutral with respect to the aforementioned idea.

\section{BRATMAN'S CONCILIATORY REACTION AND TWO PROBLEMS RAISED BY THE BELIEF CHALLENGE}

Although often neglected, there is an alternative, non-skeptical conativist reaction to the Belief Challenge that follows from Bratman's own initial discussion of intention-based coordination. ${ }^{49}$ As we saw above, several authors interpret Bratman as maintaining that the conative commitment characteristic of intention is responsible for the role that this attitude plays in coordinating action. ${ }^{50}$ This interpretation is, strictly speaking, correct. But it is also incomplete. For Bratman points out, in addition, that intention facilitates coordination because in normal cases commitment-related features of this attitude justifiably induce the belief (or "expectation") that it will be executed, and because this belief serves as a cognitive fixed point on the basis of which to plan further actions. Therefore, Bratman thinks that they are both the cited conative commitment of intention and induced belief that are responsible for the coordinating role of intention. As Bratman summarizes the point:

Intentions and plans normally support coordination in part by providing support for expectations that they will be successfully executed. My intention to go to the meeting helps support interpersonal coordination

48 For the general worry, see the classical study by Tversky and Kahneman, "Judgment under Uncertainty." On how that general worry connects to intention-related phenomena, see, e.g., Harman, "Willing and Intending," 378-80; and Bratman, Intention, Plans, and Practical Reason, 10-11.

49 Bratman, Intention, Plans, and Practical Reason, and cf. "Practical Reasoning and Acceptance in a Context."

50 E.g., see how Bratman (Intention, Plans, and Practical Reason) is interpreted by Velleman, "What Good Is a Will?" 195; and Mele, Springs of Action, 137; cf. Audi, "Intention, Cognitive Commitment, and Planning," 377n11. 
by providing support for your expectation that I will be there, an expectation that will play its role in your decision to come to the meeting. And my intention also supports my own expectation that I will be there, an expectation that allows me to plan my afternoon accordingly. Intentions and plans can provide this support for associated expectations because they are conduct-controlling pro-attitudes, ones that have a characteristic inertia, and ones that play a crucial role as inputs into and constraints on further practical reasoning. ${ }^{51}$

In advancing the just-mentioned point, Bratman acknowledges that there are two aspects to intention-based coordination: conative and cognitive. Since our interest centers on the Belief Challenge, let us concentrate on Bratman's view of the latter aspect of the phenomenon. Bratman advances two key ideas in relation to it in the quoted passage. The first is that intention-based planning is cognitively framed by belief in success. "That is," Bratman says, "a main role belief plays in ordinary planning." 52 The second is that the cited belief is normally brought about in that context by way of an inference from conative, commitment-related features of the intention, such as its tendency to control action, persist across time, and shape practical reasoning. So, according to Bratman's inferential model, one's intention to $\phi$ facilitates coordination partly by supporting an inference to the belief that one will $\phi$, which frames the formation of an intention to $\psi$ on the premise that one will $\phi$. I will say more about this inferential model below. For now, what should be clear is that for Bratman the preceding two ideas help to explain the cognitive aspect of intention-based coordination and that this explanation presupposes that in the cases in question the prior intention is accompanied by belief in success.

All this notwithstanding, we saw earlier that for Bratman intention can be accompanied instead by agnosticism about success, and so there is still the question, incisively pressed by Velleman in his formulation of the challenge, as to how intention-based coordination works in such cases. Bratman argues that intention can indeed facilitate coordination in those cases, not by supporting prior-success (or "ordinary") planning, but by supporting a more complex form of planning, which Bratman dubs "conditional" planning. ${ }^{53}$ Suppose that I am agnostic about the success of my intention to spend the weekend in Chicago and thus lack the beliefs that would permit me to engage in "ordinary" planning. In

Bratman, Intention, Plans, and Practical Reason, 37.

Bratman, Intention, Plans, and Practical Reason, 38; cf. Paul, "How We Know What We're Doing," 12.

53 Bratman, Intention, Plans, and Practical Reason, 38-40. 
such a case, Bratman suggests, I can still coordinate my activities by making my plans conditional on success. I can plan to attend the Chicago Bulls game if I go to Chicago and plan to cook dinner at home if I do not go to Chicago. Bratman's idea of conditional planning raises interesting questions but this need not detain us further here, for it is rather the phenomena of prior-success planning and coordination that is the target of the cited challenge. ${ }^{54}$

The foregoing remarks outline the main tenets of Bratman's view; however, they do not yet put us in a position to assess whether it offers a satisfactory response to the challenge. Ironically, a main obstacle is that, having taken a closer look at that view, it is now difficult to pin down the specific concerns that the challenge raises against it. At the heart of Velleman's own view and formulation of the challenge, there is the idea that the cognitive framing of intention-based planning works by way of belief in success. But, as we just saw, this idea is "central" to Bratman's view as well. ${ }^{55}$ So, if the challenge raises some specific concerns about Bratman's view, those concerns must lie elsewhere. In what follows, I identify two concerns Velleman —or the doxasticist in general—might plausibly see the challenge as raising.

One of the points Velleman rightly emphasizes in his discussion is the lack of a necessary connection between intention and intention-based planning. ${ }^{56}$ While it is true that in many cases one makes further plans on the basis of a prior intention - think, for example, of my intention to spend the weekend in Chicago-it is also true that in other cases one simply does not do this. Imagine, as Velleman illustrates, that a platter of cookies is unexpectedly held out to you and that your immediate reaction is to form an intention to grab one. In such a

54 In further work ("I Intend that We J"), Bratman contrasts between intending to $\phi$ if $p$-i.e., conditional intention - and intending to $\phi$ on the assumption that $p$-i.e., a generalization of the phenomenon under scrutiny here. The contrast is perhaps best appreciated through one of Bratman's own examples, here slightly modified: "I intend to garden on the assumption of good weather; but it seems that given [that I already assume that] the weather [will be good] I need not merely conditionally intend to garden if the weather is good" ("I Intend that We J," 158). For recent discussion of conditional intention, see esp. Ferrero, "Conditional Intentions"; and Ludwig, "What Are Conditional Intentions?"

By "central" I take Bratman to mean that this belief is not only sufficient, but also necessary to do such cognitive work (Intention, Plans, and Practical Reason, 17-18). Note that Bratman has since given up the necessity claim. In later work ("Practical Reasoning and Acceptance in a Context"), Bratman calls attention to the existence of a cognitive attitude different from belief, which he coins as "acceptance in a context" and which in his view plays a role in our practical reasoning and action similar to the one played by belief. So, in Bratman's later view, "acceptance in a context" might also be sufficient to play the role of cognitively framing intention-based planning. I explore a related, though independent, idea in section 4. 
case, Velleman notes, your intention will likely not "set the stage for any further

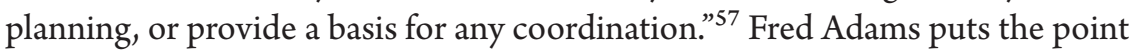
effectively: sometimes, he says, what one intends is to perform a "solitary" or "one-off" act. ${ }^{58}$ There is also a related point to be emphasized here. It seems to be a central feature of intention that, although not every instance of it does in fact facilitate intention-based planning and coordination, every instance of it can in principle do so. In other words, in intending to act in a certain way, one is disposed to-but need not in fact-make further plans on the basis of its success. And it is this last point that motivates an objection to Bratman's view on the part of the doxasticist, to the effect that the cited feature of intention is something that DC can readily explain but that Bratman's view cannot. For in the latter view the fact that one intends to do something may not be sufficient to enable an inference to the belief that one will do it, which is deemed necessary to facilitate the cited planning and coordination. So, a first concern that Velleman's challenge raises is that Bratman's view does not get the extension of intention-based planning right.

A second concern runs deeper. Velleman and Bratman agree that intention-based planning is cognitively framed by belief in success, but disagree on the genesis of such a belief. Velleman thinks that the belief in question is partly constitutive of the intention itself, whereas Bratman thinks that it is a separate attitude that comes about as a result of an inference one draws in that context from conative aspects of the intention. The second concern rests on this disagreement.

To see what the concern is, it is useful to first consider a version of doxasticism that contrasts sharply with Velleman's, the inferentialist account epitomized by Paul Grice. ${ }^{59}$ Roughly, Grice thought that the phenomenon of intending to act is a hybrid of two separate attitudes: a conative attitude of "willing" to act and a doxastic attitude of believing that one will so act. ${ }^{60}$ Most interestingly for our discussion, Grice thought also that the latter attitude of belief comes about as a result of an inference one draws from, basically, features of the former attitude of "willing." The details of Grice's view are not here to the point. What should be noted is that inferential versions of doxasticism such as Grice's are subject to a familiar objection, recently pressed by Kieran Setiya, that they break down. ${ }^{61}$ They do so because they cannot ensure that the relevant belief will be present in every instance of intending to act, and they cannot ensure this since, as Setiya

57 Velleman, "What Good Is a Will?" 198.

58 Adams, "Trying with the Hope," 144, 149; cf. Mele, Springs of Action, 140.

59 Grice, "Intention and Uncertainty."

60 Grice, "Intention and Uncertainty," 278-79.

61 Setiya, "Practical Knowledge," 394-95. 
explains, it is always "possible for the inference not to take place," as one "might simply fail to put two and two together." ${ }^{62}$

The second concern raised by Bratman's view of intention-based coordination parallels the just-mentioned objection to inferential versions of doxasticism. In Bratman's view, the belief responsible for framing one's planning on a prior intention is formed as a result of an inference one draws in such a context from some conative, commitment-based features of the latter attitude. The concern with such a view, then, is that it cannot ensure that the cited belief will ensue in every episode of intention-based planning — that is, in every case in which such a belief is needed to frame, and thus make possible, such planning. For, here as well, the relevant belief-granting inference might never be drawn. The concern is avoided by non-inferential versions of doxasticism (and of DC) such as Velleman's. On this latter view, belief in success comes about "spontaneously" with the intention, rather than as a result of an inference, and so it is guaranteed to be present whenever the intention is present and therefore whenever one is engaged in intention-based planning. ${ }^{63}$

To be sure, it is clear that the conativist might not grant legitimacy to the two concerns raised by Velleman's Belief Challenge, since such concerns, as so far formulated, hang on a thesis they reject, namely, the thesis that intention involves belief. Be that as it may, I think it would be a serious mistake for the conativist to completely disregard those concerns. For I think that such concerns can be formulated in a way that is independent of doxasticism and that, when so formulated, they help to articulate two genuine problems for extant conativist accounts of intention-based coordination (cc).

A first problem is directed at cases in which, as the conativist sees it, intention is accompanied by agnosticism about success. It seems to be an essential feature of intention, I suggested above, that every instance of it can in principle facilitate intention-based planning and coordination. Cases of intending without believing are genuine instances of intending, and so they possess that feature as well. ${ }^{64}$ But if intention-based planning is possible in the context of agnosticism about success, how could the conativist account for it, given the common presumption that such planning is cognitively framed by belief? The conativist has available

62 Setiya, "Practical Knowledge," 394; cf. Velleman, Practical Reflection, ch. 2.

63 Velleman, Practical Reflection, ch. 2. According to the present objection, inferentialist versions of doxasticism, such as Grice's, would be susceptible to the Belief Challenge as well.

64 Mele is therefore right in claiming, as I argue in section 4, that intention-based planning is possible even in the presence of serious doubts about success. What Mele fails to acknowledge, however, is that, even in this context, intention-based planning involves planning on the premise of success. 
an explanation of the cognitive framing of intention-based planning for cases in which intention is accompanied by belief in success, but seems powerless to explain how that cognitive work is accomplished when intention is not so accompanied. So, to put it in general terms, a problem for conativism is to offer an extensionally adequate account of intention-based planning. Call this the "problem of extension" for CC. A second problem is directed at cases in which, as conativists such as Bratman and Brunero acknowledge, intention-based planning is cognitively framed by belief in success. As we saw a moment ago, there is a question as to what can ensure the presence of such a belief in those cases and the worry is that the only answer apparently available to the conativist-i.e., an appeal to a relevant inference-is unable to explain this. Thus, a second problem for the conativist, stated broadly, is to explain why the cognitive attitude deemed responsible for the framing of intention-based planning on a certain occasion will in fact be present on that occasion. Call this the "problem of presence" for CC. In section 4, I propose an alternative and, hopefully, more illuminating conception of the cognitive framing of intention-based planning, one that affords conativism with satisfactory answers to the aforementioned two problems.

Before proceeding, however, I would like to note that the foregoing discussion also provides further support for the Independence Thesis. It indicates that our answer to the question of the cognitive constraints on intention-based planning does not force on us a specific answer to the question of the cognitive constraints on intending, and thus it points to another respect in which such questions are distinct. From the claim that there is a certain cognitive constraint on intention-based planning it does not follow that there is a parallel cognitive constraint on mere intending on which the former constraint necessarily depends. Indeed, the foregoing discussion indicates that our answer to the former question is compatible with multiple, and even opposing, answers to the latter. At this point I think we can appreciate how the thesis affords a deeper insight into competing views of intention-based planning. It helps us to see, for example, that in order to vindicate DC, the doxasticist must do more than establish that planning on a prior intention involves believing that such an intention will be successfully executed; for to establish this is not thereby to establish that the cited belief must be partly constitutive of the intention. It also casts further light on the contrast between the views by Bratman, Velleman, and Mele. It allows us to portray Bratman's view as occupying a middle position between the other two. Bratman claims - like Velleman but unlike Mele—that planning on a prior intention requires belief in success; but he also maintains-like Mele but unlike Velleman - that mere intending does not require this. Thus, Bratman thinks with Mele, against Velleman, that "there is nothing about coordinative capacity 
itself that calls for [relevant] belief constraints on intention," but he also believes with Velleman, against Mele, that there is something "about coordinate capacity itself that calls for" a relevant belief constraint on intention-based planning. ${ }^{65}$

\section{INTENTION, FURTHER PLANNING, AND RELIANCE}

\subsection{Introduction: An Alternative Proposal}

Our discussion so far supports the idea of the existence of a coordination-facilitating form of intention-based planning, namely, prior-success planning. According to this form of planning - henceforth, "intention-based planning"- to plan to $\psi$ on the basis of one's prior intention to $\phi$ is to plan to $\psi$ on the premise that one will $\phi$. We saw that the idea is endorsed by doxasticists such as Velleman as well as by conativists such as Bratman. ${ }^{66}$ We also saw that Velleman and Bratman endorse in addition a fundamental, if somewhat implicit, idea about the psychology of intention-based planning, and this is that forming the intention to $\psi$ on the premise that one will $\phi$ is nothing but to form such an intention on the belief that one will $\phi .{ }^{67}$ Hence their suggestion that intention-based planning works by way of belief.

My account of the cognitive aspect of intention-based coordination starts by rejecting the last-mentioned idea. I claim that although Velleman and Bratman are right in suggesting that one's intention to $\phi$ facilitates intention-based coordination in part because it allows one to form further intentions on the premise that one will $\phi$, they are wrong in supposing that forming further intentions on the premise that one will $\phi$ need involve forming such intentions on the basis of the belief that one will $\phi$. I contend that a different type of flat-out cognitive attitude, the attitude of reliance, can and does play this cognitive role. More broadly, my thesis is that the cognitive framing of intention-based planning is better understood in terms of reliance than in terms of belief. Planning to act on the basis of a prior intention is better understood as planning to act in reliance on the execution of that prior intention than as planning to act in the belief that such a prior intention will be executed. Earlier I called this the Reliance Thesis. In what follows, I argue for this thesis in part by showing how it answers the two problems we raised for $\mathrm{CC}$ at the end of section 3 : the problem of extension and the problem of presence.

65 Mele, Springs of Action, 138.

66 Velleman, "What Good Is a Will?"; Bratman, Intention, Plans, and Practical Reason.

67 Though see note 55 . 


\subsection{Reliance: What Is It? And When Is It Justified?}

As a first step toward addressing such problems, it is important to set out a conceptual framework for thinking systematically about reliance and its relation to belief. Here I offer an outline of an independently plausible theory of reliance, which I have developed in more detail elsewhere. ${ }^{68}$ In my view, reliance is a cognitive attitude such as belief, rather than a conative attitude such as desire. ${ }^{69} \mathrm{Re}$ liance is also like belief in that it typically plays the role of cognitively guiding or framing one's reasoning. In particular, relying on $p$ disposes one to deliberate, plan, and act on the premise that $p$. Suppose that I want to climb down a rock and that I am wondering whether a piece of rope will hold my weight. If under such conditions I rely on the rope's holding my weight, I will be disposed to, for example, form the intention to climb down the rock, deliberate about what strategy to employ in my descent, and make certain moves, all based on the premise that the rope will hold my weight. In these two respects reliance and belief are alike.

Reliance also differs from belief in important ways, however. A key difference for our purposes is that such attitudes are subject to different norms of correctness. While belief is correct just in case it is true, reliance is correct just in case it provides what I call "sensible guidance," that is, just in case it cognitively guides one's reasoning in a way that is instrumental to one's relevant ends and values. ${ }^{70}$

To get a grip on what the norm of sensible guidance for reliance amounts to, it is useful to first consider some aspects of the descriptive, factual relation between reliance and truth. It seems clear that in some cases one's reliance is directed at - that is, functions so as to track - the truth. Roughly, to say that one's reliance on $p$ is directed at the truth in some cases is to say that in those cases one is disposed to rely on $p$ only if $p$ is the case. For example, my reliance on the rope's holding my weight is directed at reflecting whether the rope actually

68 See, Alonso, "What Is Reliance?" and "Reasons for Reliance." For alternative views of reliance, see among others, Railton, "Reliance, Trust, and Belief”; and Marušić, “Trust, Reliance, and the Participant Stance." The significance of reliance to our thought and action is not limited to its role in prior-success planning, as I hope will be apparent from the discussion below.

69 Some philosophers assimilate the phenomenon of relying on $p$ to the mental act of using $p$ in one's reasoning (cf. Williamson, Knowledge and Its Limits, 99). In my view, in contrast, reliance is a mental state that generally involves such a mental act, but is not to be identified with it.

70 See, e.g., Williams, "Deciding to Believe"; and Shah and Velleman, "Doxastic Deliberation." In this paper I am also assuming an evidentialist conception of reasons for belief, where such reasons include reasons for beliefs about what is intended. Cf. Velleman, Practical Reflection; and Marušić and Schwenkler, "Intending Is Believing," 314-16. 
holds my weight, and thus I am disposed to continue to so rely as long as I do not find (perhaps conclusive) evidence that the rope will not hold my weight. Nevertheless, there are some other cases in which reliance is not directed at the truth. In those cases, one is not disposed to rely on $p$ only if $p$. Rather than being directed at representing some actual state of affairs, in those other cases reliance is directed at picturing — or presenting to one's mind—some non-actual state of affairs as obtaining. Imagine a mathematician who assumes that $p$ - that is, relies on $p$ - for the purposes of a reductio. ${ }^{71}$ It is plain that, in the context of constructing such a proof, the mathematician may rely on $p$ without much concern as to whether $p$ is true or, even, while thinking that $p$ is false.

Consider next a central aspect of the factual relation between reliance and cognitive guidance. Reliance can play its characteristic role of cognitively guiding one's reasoning irrespective of whether it is also playing a truth-tracking role. When one's reliance on $p$ is directed at the truth, it guides one's reasoning on the basis of $p$, but when it is not directed at the truth, it guides one's reasoning on the basis of $p$ just the same. In both cases one is disposed to deliberate, plan, and act on the basis of $p$. When I rely on the rope's holding my weight, my reliance frames my reasoning accordingly. I intend to climb down a rock, deliberate about different climbing strategies, and make certain moves, in light of the premise that the rope will hold my weight. But when the mathematician relies on $p$ for the purposes of an indirect proof, her reliance guides her reasoning accordingly, too. She structures her proof on the basis of, and draws conclusions from, the premise that $p$.

From the preceding considerations we can conclude that there are two ways in which reliance may provide sensible guidance-that is, cognitive guidance that is instrumental to one's relevant end. First, reliance may provide sensible guidance in part by being successful in tracking the truth. More precisely, one's reliance on $p$ may sensibly guide one's reasoning only if (a) one relies on $p$ only if $p$ and (b) $p$ is true. My reliance on the rope's holding my weight may frame my deliberation, planning, and action in ways conducive to my end of climbing down the rock only if the rope actually holds my weight and my reliance accurately reflects that fact. Call this form of sensible guidance, "truth-directed sensible guidance." Second, reliance may provide sensible guidance without being responsive to the truth. Specifically, one's reliance on $p$ may sensibly guide one's reasoning even if it is the case neither that (a) one relies on $p$ only if $p$ nor that (b) $p$ is true. The mathematician's non-truth-directed reliance on $p$ may guide her reasoning in ways conducive to her end of constructing the desired proof, even if $p$ is false and her reliance is impervious to that fact in that con- 
text. This is because the attainment of her end does not require that $p$ be true. Call this, "non-truth-directed sensible guidance." Having drawn this contrast, it should be noted that it is the former form of sensible guidance, truth-directed sensible guidance, that is of particular interest to our present discussion, as intention-based-i.e., prior-success_coordination will be possible only if one's reliance on the successful execution of one's intention is directed at and succeeds in tracking the truth.

The contrast, regarding norms of correctness, between reliance and belief explains other differences between such attitudes. One of them has to do with the normal functioning of such attitudes. Since reliance and belief are subject to the norms of, respectively, sensible guidance and truth, they integrate and prioritize the functions of tracking the truth and of providing sensible guidance in different ways. The primary role of belief is to track the truth, although this attitude sometimes also plays, partly in virtue of performing such a primary role, a secondary role of providing (truth-directed) sensible guidance. Alternatively, the primary role of reliance is to provide either truth-directed or non-truth-directed sensible guidance, although in order to provide the former form of guidance this attitude must also play a secondary role of tracking the truth.

The cited contrast also sheds light on the conditions under which such attitudes are justified. The truth-norm for belief indicates that this attitude is justified by, and only by, evidence for its truth, whereas the norm of correctness for reliance establishes that this attitude is justified by, and only by, considerations about sensible guidance. ${ }^{72}$ To put the last point in more precise terms:

Justification of Reliance ( $\mathrm{JR}$ ): One is justified in relying on $p$ in context $C$ only if (1) one has a relevant end in context $C$ and (2) one has good reasons for believing that relying on $p$ is a-productive or constitutivemeans to attaining one's end.

Two features of schema JR are relevant to our discussion below. First, although it applies to cases of truth-directed guidance and cases of non-truth-directed guidance alike, this schema also registers an important dissimilarity between such cases. In cases of truth-directed guidance, but not in cases of non-truth-directed guidance, one's reliance on $p$ will satisfy condition 2 of schema JR only if it satisfies, in addition, an evidential constraint. The constraint is that (3) one lacks sufficient evidence for believing that not $p$-that is, for believing that what one relies on is false. ${ }^{73}$ The rationale for this constraint is straightforward. Since in

Here, as well as elsewhere (Alonso, "Reasons for Reliance"), I concentrate only on necessary — rather than on necessary and sufficient—conditions for reliance justification.

Although I think that this is a plausible construal of the constraint and have appealed to 
such cases the instrumentality of relying on $p$ is a function of the truth of $p$, not having sufficient evidence to believe that $p$ is false indicates that relying on $p$ might provide sensible guidance after all. Therefore, we may say that in cases of truth-directed guidance the conditions for reliance justification include not only conditions 1 and 2 of schema JR but also an additional condition implicit in 2, namely 3. Second, in specifying the conditions for reliance justification in the cited way, schema JR brings into sharper focus how the justification of this attitude differs from the justification of belief. It allows us to see, first, that while belief can be justified solely by evidence for its truth, reliance can be justified on the basis of both evidential and pragmatic considerations; and, second, that while the justification of belief requires having sufficient evidence for its truth, the justification of reliance in cases of truth-directed guidance requires only that one lack sufficient evidence for its falsity.

Finally, another key difference between reliance and belief that matters for our purposes is that the former attitude can be under the control of the will in a way in which the latter cannot. One can on reflection form the attitude of reliance for (what one takes to be) a practical reason, or perhaps even arbitrarily, but one cannot similarly form the attitude of belief. ${ }^{74}$ To say that reliance can be under the control of the will is compatible with acknowledging that in some cases evidence can set a psychological — rather than a metaphysical or conceptuallimit on what one may rely on. Granted, it may be difficult for one to consciously come to rely on $p$ if one has overwhelming evidence against $p$ and one's reliance is aimed at providing truth-directed guidance; and it may also be unjustified. But it is surely not impossible. In contrast, it is commonly thought that evidence sets a metaphysical or conceptual—rather than merely a psychological—restriction on what one can "in full consciousness" come to believe. ${ }^{75}$

it in earlier work (Alonso, "Reasons for Reliance"; cf. Wright, "Warrant for Nothing (and Foundations for Free)?"), I now believe that a weaker construal might do as well. Perhaps all that is required is that one have credence greater than zero that $p$.

74 On my view, practical reasons for truth-directed reliance are a function of the truth of what is relied on. The fact that relying on the rope holding my weight is a means to my end of my climbing down the rock, entails that it is a fact that the rope holds my weight. For discussion, see Alonso, "Reasons for Reliance."

75 Williams, "Deciding to Believe." Some doxasticists (Velleman, Practical Reflection; Marušić and Schwenkler, "Intending Is Believing") claim that the restriction does not apply to beliefs about what one intends, but I am not convinced. Thanks to an anonymous reviewer for urging me to clarify this. 


\subsection{Is Reliance on Success Sufficient to Do the Cognitive Work in Intention-Based Coordination?}

With such a theory of reliance in hand, let us return to the question of intention-based planning and coordination. Given the functional profile of reliance, it is clear that reliance on the successful execution of one's prior intention can cognitively frame the planning of further activities for the future, as well as one's deliberation and action, on the premise that one's prior intention will be executed. Suppose that I intend to spend this weekend in Chicago and am deliberating about what to do on Saturday evening. Suppose also that I would like to attend the Bulls game that evening. If in that scenario I relied on the successful execution of my intention to be in Chicago this weekend, I would be disposed to, for example, form the intention to attend the Bulls game on Saturday evening, deliberate about ways to get to the stadium, and eventually proceed to act, all based on the premise that I will be in Chicago this weekend. Furthermore, it is also clear that one's reliance on the successful execution of one's prior intention can play such a framing role in contexts in which one does not possess the corresponding belief. Suppose, once again, that briefly before flying to Chicago, I discover that airline workers are deliberating about whether to go on strike. Suppose also that in this new scenario I continue to intend to spend the weekend in Chicago, but now have doubts as to whether I will do so. On reflection, I do not believe that I will be in Chicago this weekend. But I do not believe that I will not be there then, either. My evidence, which includes the new information, justifies neither belief. Notwithstanding this, in the new scenario I may still rely on my spending the weekend in Chicago and plan my activities for the weekend on the basis of such reliance. In particular, I may form the intention to attend the Bulls game on Saturday evening — and, say, proceed to buy a ticket for it—in reliance on my being there. ${ }^{76}$

Still, it is important to recall that a central concern in this paper is with the issue of how the cognitive framing of intention-based planning can facilitate successful coordination and so a question arises for the Reliance Thesis as to how reliance on success can secure this. Return to the previous example. It seems that I will attend the game on Saturday as a result of successful coordination if the following conditions are met:

Surely, in such a scenario I might also try to protect myself against failure and form a backup plan. E.g., I might buy a refundable ticket for the game and form the conditional intention to cook dinner at home if it turns out that I am not in Chicago. See note 54. Thus, in this scenario I might engage in both prior-success planning and conditional planning. These remarks have benefited from valuable comments by two anonymous reviewers. 
a. My reliance cognitively frames (and thus helps to make possible) the formation of my intention to attend the game.

b. My intention to spend the weekend in Chicago is successfully executed.

c. My reliance accurately reflects this fact-that is, the fact stated in b.

d. My intention to attend the game is executed as well.

That indicates that my reliance will be conducive to my actually attending the Bulls game by playing two main roles ( $\mathrm{a}$ and $\mathrm{c}$ ), the roles of cognitively guiding my planning and of tracking the truth. Therefore, the answer to the aforementioned question is that reliance on success can secure successful coordination by providing truth-directed sensible guidance. ${ }^{77}$ In such cases, our theory of reliance tells us, reliance on success will be correct.

Accordingly, our theory of reliance also helps to explain why in planning on a prior intention one may be justified in relying on its success, even if one would not be justified in having the corresponding belief. Thus, schema JR indicates that in the aforementioned scenario I may be justified in relying on the success of my intention to spend the weekend in Chicago. For in that scenario, (1) I have a relevant end, namely, to coordinate my future planning and action in ways that lead to my (planning to attend and to my eventually) attending the Bulls game; and (2) I may also have good reasons for believing that relying on the successful execution of my intention to spend the weekend in Chicago is instrumental to that end-where such reasons include (3) my lacking sufficient reasons for believing that such an intention will not be executed. To appreciate why I may have the good reasons alluded to in 2, it is useful to look at the conditions that determine the instrumentality (and hence the correctness) of my reliance in that context. Those are mainly conditions a-c, mentioned in the paragraph above. It is clear that in that scenario I may have good reasons for believing that my reliance will be functioning properly, that is, that it will (a) cognitively frame my planning and (c) track the truth. And it is stipulated that in that scenario I have evidence indicating that there is a chance, perhaps a non-negligible chance, that (b) my intention will be executed.

\subsection{Is Reliance on Success Necessary to Do the Cognitive Work in Intention-Based Coordination?}

Having argued, on the basis of our theory of reliance, that reliance on success is sufficient to do the cognitive work in intention-based planning and coordinaguidance. For discussion of related cases, see Alonso, "What Is Reliance?" and "Reasons for Reliance." 
tion, I want to argue next that such a theory also provides us with valuable resources for solving the two problems for conativist accounts of such phenomena (cc) raised at the end of section 3. Start with the problem of presence for CC. The task, recall, is to show that the attitude deemed responsible-i.e., sufficientfor cognitively framing intention-based planning on a certain occasion-on the present proposal, reliance on success - will indeed be present on that occasion. So, how can we show this?

An obvious approach is to seek a parallel with DC. The idea is to posit the existence of a necessary connection between intention and reliance on success and to then construct a version of $\mathrm{CC}$ on the basis of it. According to this idea, reliance on the success of a prior intention is guaranteed to be present on every occasion in which it frames one's planning on that prior intention because in having such an intention one inexorably relies on its success. Despite its apparent simplicity, however, I am skeptical of this approach. Here are two reasons why. First, it is not clear to me that there exists a necessary connection between intention and reliance on success. Second, even if such a necessary connection exists, it is not clear that we need to appeal to it in order to account for the cognitive framing of intention-based planning. We know that there is not a necessary connection between intention and intention-based planning (recall Velleman's cookie example), and so it is difficult to see why accounting for the latter phenomenon would mandate positing a necessary connection between intention and reliance on success.

Our discussion in section 3 indicates that there is another approach that will not do. We cannot explain why reliance on success is guaranteed to be present on every occasion in which it frames intention-based planning by seeking to construct an inferentialist account of it, in a way that parallels Bratman's inferentialist model of the presence of belief in success in intention-based planning. ${ }^{78}$ For the resulting inferentialist account, whatever its specific shape, would fail to explain the presence of reliance on success on every such occasion, as the relevant inference might never be drawn. ${ }^{79}$

In contrast to such approaches, I argue that what secures the presence of reliance on success on such occasions is the fact that, in planning on a prior intention, one necessarily relies on its success. To provide support for the idea of the existence of a necessary connection between planning on a prior intention and relying on its success, we must provide reasons for thinking that such a connec-

78 Bratman, Intention, Plans, and Practical Reason.

79 In previous work, I gestured toward one such an inferential account (Alonso, "Intending, Settling, and Relying," 72). My current approach acknowledges that inference is only one route to reliance on success in that context. 
tion holds both in cases in which the prior intention is accompanied by belief in success and in cases in which it is not. Start with the latter cases. There are two reasons for thinking that in such cases reliance on success will be present and cognitively guide one's intention-based planning. First, it seems that in such cases one can come to rely on success at will-viz., come to so rely for the purposes of framing such planning and in the absence of evidence that would justify the formation of the corresponding belief. Second, it is plausible to think that only a reliance-involving attitude will be present and able to do the requisite cognitive work in such cases, as the cited attitude will have to bear a relation to the will and to cognitive guidance of the sort that is distinctive of reliance. Consider now the former cases. I claim that reliance on success cognitively frames intention-based planning also when in the presence of belief in success. This might seem surprising, as belief in success is commonly thought to be responsible for the framing of such planning whenever it is present in that context. Yet the claim is less surprising once we realize that in contexts of intention-based planning belief in success gives way to reliance on success. Suppose that I do in fact believe that my intention to be in Chicago this weekend will be successfully executed and form the intention to attend the game on the premise that I will be there. In that case, my belief is not merely responding to my general thirst for knowledge, but is primarily framing my intention-forming process. And, as soon as my belief begins to play this framing role, it gives way to a mental state that is typically guided by, and can be appropriately assessed in terms of, its instrumentality in playing such a role, that is, it gives way to an attitude of reliance.

Therefore, if we accept, as suggested in section 2.1, that prior-success planning is planning on the "assumption" or cognitive attitude that one's prior intention will be successful, and we accept, as argued above, that reliance on success cognitively frames prior-success planning both in the absence and in the presence of the corresponding belief (or relevant evidence), I think we can plausibly conclude that the aforementioned "assumption" is or involves reliance, and consequently that there is a necessary connection between planning on a prior intention and relying on its success. Note that to say that in planning on a prior intention one necessarily relies on its success is not to say that one is always justified in so relying. Certainly, one normally comes to so rely for the purposes of cognitively framing such planning and facilitating coordination; but one may come to so rely while lacking good reasons for believing that one's reliance will in fact play such a facilitating role. In other words, although cases of intention-based planning normally satisfy the first condition that schema JR sets for reliance justification, they do not always satisfy its second condition. I may be justified in relying on my being in Chicago this weekend even though I do not 
have sufficient evidence for believing that I will be there. But I might not be so justified were I to have overwhelming evidence that the airline strike would continue during the weekend.

We just saw that the Reliance Thesis and the theory of reliance that undergirds it answer the problem of presence for Cc by supporting the conclusion that reliance on success is not only sufficient, as argued in section 4.3, but also necessary to cognitively frame intention-based planning. The next thing to note is that, by supporting such a conclusion, the Reliance Thesis and accompanying theory provide an answer to the problem of extension for $\mathrm{CC}$ as well. For that conclusion indicates that reliance on success will be available in every instance of intention-based planning - whether or not there is agnosticism about such success - and be able to do the cited cognitive work. Finally, we should note also that the answers that the Reliance Thesis offers to the cited two problems are consonant with the Independence Thesis, for such answers rest on the idea that planning on a prior intention necessarily involves relying on its success and this idea is neutral with respect to the further question of whether the prior intention itself necessarily involves such reliance. The version of CC that the Reliance Thesis supports is not the reliance analogue of DC.

I want to close this section by connecting the foregoing discussion with the decision-theoretic account of intention-based planning considered in section 2.3. According to that account, recall, one is disposed to plan one's further activities on the success of one's prior intention when the expected value of one's so planning is sufficiently high. The idea is that in such cases one's relevant credences and evaluative judgments jointly induce a full cognitive attitude in favor of success, which is responsible for framing the cited planning in that context. A deficit of that account, we noted earlier, is that it does not identify what full cognitive attitude that is. What I want to add here is that the reliance-based account defended above not only identifies reliance on success as the attitude responsible for doing that cognitive work, but also allows for the possibility that such reliance is, on some occasions, a consequence of a relevant set of credences and evaluations. This possibility is consistent with conceiving of reliance on success as playing, as the foregoing discussion indicates, an independent cognitive role in intention-based planning and, more broadly, with conceiving of reliance as a psychologically fundamental attitude.

\section{CONCLUDING REMARKS}

In this paper I have called attention to the significance and relative independence of the question of the cognitive constraints on the coordinating role of intention. 
The answer to that question, I have argued, does not simply fall out of an answer to the question of the cognitive constraints on mere intending. In addition, I have contended that an adequate answer to the former question is provided by a theory of reliance of the sort I have outlined here. Such a theory supports the thesis that it is reliance on success, rather than belief in success, that is responsible for cognitively framing one's intention-based planning and coordination. In so doing, the theory also provides an indirect argument for conativism. It offers an explanation of the cognitive aspect of intention-based coordination that is compatible with conativism, and at the same time undercuts an argument generally offered in support of its rival, doxasticism, to the effect that it is only by endorsing the thesis that intention involves belief that we can explain how intention plays its characteristic planning and coordinating roles. A question for further inquiry is whether such a theory can similarly shed light on other central issues in the philosophy of action, also disputed between doxasticists and conativists, such as the questions of the distinguishing marks of intentional action and of the grounds of the norms of intention rationality. ${ }^{80}$

Miami University, Ohio alonsofm@miamioh.edu

\section{REFERENCES}

Adams, Frederick. "Trying with the Hope." In Rationality and the Good, edited by Mark Timmons, John Greco, and Alfred Mele, 143-62. Oxford: Oxford University Press, 2007.

Alonso, Facundo. "Intending, Settling, and Relying." In Oxford Studies in Agency and Responsibility, vol. 4, edited by David Shoemaker, 50-74. Oxford: Oxford University Press, 2017.

—_. "Reasons for Reliance." Ethics 126, no. 2 (January 2016): 311-38. . "Shared Intention, Reliance, and Interpersonal Obligations." Ethics 119, no. 3 (April 2009): 444-75.

- "What Is Reliance?" Canadian Journal of Philosophy 44, no. 2 (April 2014): 163-83.

80 I would like to thank Franz Altner, Olle Blomberg, John Charles, Margaret Gilbert, Michael Hicks, Christopher King, Carlos Núñez, Herlinde Pauer-Studer, Gaile Pohlhaus, and audiences at the University of Vienna and at Miami University, Ohio for valuable discussion. Special thanks to Samuel Asarnow, Michael Bratman, and three anonymous reviewers for this journal for extremely helpful written comments. 
Audi, Robert. "Intending." Journal of Philosophy 70, no. 13 (July 1973): 387-403.

- "Intention, Cognitive Commitment, and Planning." Synthese 86 (1991): $361-78$.

Bratman, Michael. Faces of Intention. Cambridge, MA: Cambridge University Press, 1999.

_. "I Intend that We J." In Faces of Intention, 142-61.

_. "Intention, Belief, Practical, Theoretical." In Planning, Time, and SelfGovernance, 18-51.

- Intention, Plans, and Practical Reason. Cambridge, MA: Harvard University Press, 1987.

- Planning, Time, and Self-Governance: Essays in Practical Rationality. Oxford: Oxford University Press, 2018.

—. "Practical Reasoning and Acceptance in a Context." In Faces of Intention, $15-34$.

- "Rational and Social Agency: Reflections and Replies." In Vargas and Yaffe, Rational and Social Agency, 294-343.

- Shared Agency: A Planning Theory of Acting Together. Oxford: Oxford University Press, 2014.

- "Shared Intention." In Faces of Intention, 15-34.

Brunero, John. "Cognitivism about Practical Rationality." In Oxford Studies in Metaethics, vol. 9, edited by Russ Shafer-Landau, 18-44. Oxford: Oxford University Press, 2014.

Davidson, Donald. "Intending." In Essays on Actions and Events, 83-102. Oxford: Oxford University Press, 1980.

—. "Reply to Pears." In Vermazen and Hintikka, Essays on Davidson, 211-15. Davis, Wayne. "A Causal Theory of Intending." In The Philosophy of Action, edited by Alfred Mele, 131-48. Oxford: Oxford University Press, 1997.

Ferrero, Luca. "Conditional Intentions." Noûs 43, no. 4 (December 2009): 70041.

Grice, Paul. "Intention and Uncertainty." Proceedings of the British Academy 57 (1971): 263-79.

Harman, Gilbert. "Practical Reasoning." Review of Metaphysics 29, no. 3 (March 1976): 431-63.

- "Willing and Intending." In Philosophical Grounds of Rationality, edited by Richard E. Grandy and Richard Warner, 363-80. Oxford: Oxford University Press, 1986.

Holton, Richard. "Intention as a Model for Belief." In Vargas and Yaffe, Rational and Social Agency, 12-37. 
. "Partial Belief, Partial Intention.” Mind 117, no. 465 (January 2008): 27-58.

Ludwig, Kirk. "Impossible Doings." Philosophical Studies 65, no. 3 (March 1992): $257-81$.

- "What Are Conditional Intentions?" Methode: Analytic Perspectives 4, no. 6 (2015): 30-6o.

Marušić, Berislav. "Belief and Difficult Action." Philosophers' Imprint 12, no. 18 (December 2012): 1-30.

- "Trust, Reliance, and the Participant Stance." Philosophers' Imprint 17 (August 2017): 1-10.

Marušić, Berislav, and John Schwenkler. "Intending Is Believing: A Defense of Strong Cognitivism." Analytic Philosophy 59, no. 3 (September 2018): 309-40. McCann, Hugh. "Settled Objectives and Rational Constraints." American Philosophical Quarterly 28, no. 1 (January 1991): 25-36.

Mele, Alfred. Springs of Action. Oxford: Oxford University Press, 1992.

Paul, Sarah. "How We Know What We're Doing." Philosophers' Imprint 9, no. 4 (October 2009): 1-24.

Pears, David. "Intention and Belief." In Vermazen and Hintikka, Essays on Davidson, $75^{-88 .}$

Railton, Peter. "Reliance, Trust, and Belief." Inquiry 57, no. 1 (2014): 122-50.

Ross, Jacob, and Mark Schroeder. "Belief, Credence, and Pragmatic Encroachment." Philosophy and Phenomenological Research 88 (March 2014): 259-88.

Schwitzgebel, Eric. "A Phenomenal, Dispositional Account of Belief." Noûs 36, no. 2 (June 2002): 249-75.

Setiya, Kieran. "Cognitivism about Instrumental Reason." Ethics 117, no. 4 (July 2007): 647-73.

_. "Practical Knowledge." Ethics 118, no. 3 (April 2008): 388-409.

—. "Practical Knowledge Revisited." Ethics 120, no. 1 (October 2009): 12837.

- Reasons without Rationalism. Princeton: Princeton University Press, 2007.

Shah, Nishi, and J. David Velleman. "Doxastic Deliberation." Philosophical Review 114, no. 4 (October 2005): 497-534.

Tuomela, Raimo, and Kaarlo Miller. "We-Intentions." Philosophical Studies 53, no. 3 (May 1988): 367-89.

Tversky, Amos, and Daniel Kahneman. "Judgment under Uncertainty: Heuristics and Biases." Science 185, no. 4157 (September 27, 1974): 1124-31.

Vargas, Manuel, and Gideon Yaffe, eds. Rational and Social Agency: Essays on the Philosophy of Michael Bratman. Oxford: Oxford University Press, 2014. 
Velleman, J. David. “The Guise of the Good," In The Possibility of Practical Reason, 99-122.

- "On the Aim of Belief." In The Possibility of Practical Reason, 244-81.

- The Possibility of Practical Reason. Oxford: Oxford University Press, 2000.

- Practical Reflection. Princeton: Princeton University Press, 1989.

- Review of Intention, Plans, and Practical Reason, by Michael Bratman. Philosophical Review 100, no. 2 (April 1991): 277-84.

- "What Good Is a Will?" In Action in Context, edited by Anton Leist, 193-215. Berlin: Walter de Gruyter, 2007.

Vermazen, Bruce, and Merrill B. Hintikka, eds. Essays on Davidson: Actions and Events. Oxford: Clarendon Press, 1985.

Williams, Bernard. "Deciding to Believe." In Problems of the Self, 136-51. Cambridge: Cambridge University Press, 1973.

Williamson, Timothy. Knowledge and Its Limits. Oxford: Oxford University Press, 2000.

Wright, Crispin. “Warrant for Nothing (and Foundations for Free)?” Aristotelian Society Supplementary Volume 78, no. 1 (July 2004): 167-212. 